\title{
Who is the Blockchain Employee? Exploring Skills in Demand using Observations from the Australian Labour Market and Behavioural Institutional Cryptoeconomics
}

\author{
${ }^{1}$ Jessica Atherton, ${ }^{2}$ Alexandra Bratanova, ${ }^{3}$ Brendan Markey-Towler \\ 1,2Commonwealth Scientific and Industrial Research Organisation's Data61, Australia \\ ${ }^{3}$ Independent researcher, Australia
}

Correspondence: jessica.atherton@data61.csiro.au

Received: 26 March 2020 Accepted: 13 May 2020 Published: 19 June 2020

\begin{abstract}
LinkedIn recently predicted that blockchain skills will be the most in-demand skill in 2020, and in 2018 blockchain led the list of the fastest growing skills in demand according to Upwork. But what exactly constitutes the skill set of a blockchain employee? We use Australian labour market data to explore what skills are in demand among the blockchain workforce. We also take a deeper dive and explore what educational qualifications and experiences are required of blockchain employees, and how blockchain-related jobs perform on salary scales. We discover that alongside 'hard' software engineering skills such as programming languages or computer science, blockchain-related jobs require candidates to have 'soft' skills such as creativity, communication and leadership. To explain this, we use institutional cryptoeconomics, applied game theory and applied behavioural science to suggest that the demand for skills may be understood as a function of challenges to blockchain adoption. We suggest that for blockchain to enter a mass adoption phase, the industry will need employees with an integrated skill set of both hard software engineering skills and soft behavioural or enterprise skills. Furthermore, blockchain leaders, community leaders and end users will need to gain 'blockchain literacy' to overcome the challenge of coordinating expectations by developers and users, who will create network externalities and facilitate rapid, coordinated adoption. We contribute to the evidence-based blockchain literature by using Australian labour market data to derive insight into the challenges posed to the adoption of blockchain as (and if) it climbs out of the current 'trough of disillusionment'.
\end{abstract}

Keywords: blockechain; skill set; technology adoption; labour market; cryptoeconomics

JEL Classifications: O10, O40, J01, H30, A1

\section{Introduction}

Blockchain ${ }^{1}$ can potentially transform the Australian and global economy by offering greater data transparency, improved traceability, enhanced security and reduced costs across a variety of industries [2-4]. Blockchain allows users to transfer value efficiently in the absence of trusted intermediaries, and it has the potential to form a basis for an 'Internet of Value' by overcoming issues of trust in an online environment [5]. It has the potential to serve as a new type of inter-institutional infrastructure transforming the roles of traditional institutions including governments, firms, clubs, commons and indeed

1 According to the Crypto Encyclopedia, a blockchain is 'a publicly accessible distributed ledger that was initially designed and implemented to enable Bitcoin transactions. It is a piece of information technology infrastructure that serves as a database which is used to keep a continuously growing list of records, so called blocks' [1]. markets themselves [6]. Whether these changes can be realised is a question predicated on the level of adoption of blockchain as a technology for economic interaction [7].

This article investigates which skills are in demand for blockchain employees as the technology progresses beyond the initial hype that typically follows the introduction of a new technology, through the notorious 'trough of disillusionment' and finally into a 'plateau of productivity' - where most of the substantial economic gains can be produced [8]. To do this, we explore two data sets from the Australian labour market in 2015-2019. We then seek a theoretical explanation for our observations. This approach can be seen as phenomenological [9], and we indeed want the readers to experience and explore the data and hence observe phenomena before we position the theory to explain them. We provide the theoretical explanation by drawing on institutional cryptoeconomics, applied game theory and applied behavioural science to explain our observations as a function of the challenges to blockchain adoption. We also discuss the future challenges that Australia might face in meeting the fast-growing 
demand for blockchain employees seeking to solve the broader problem of securing blockchain adoption.

We first consider the emergence of blockchain jobs globally and in Australia in line with the 'hype cycle'. We then explore data sets on blockchain-related job ads and required skills. Next, we explain our observations drawing on the perspective of behavioural institutional cryptoeconomics. Finally, we discuss the broader significance of our results.

\section{Blockchain hype and skills demand: a historical review}

There is no industry in the world today that has not investigated the opportunities of blockchain. In just a decade the technology has facilitated the creation of new products and services in Australia and internationally. Between 2014 and 2018, worldwide venture capital funding of blockchain grew by a factor of 11 to US $\$ 5.6$ billion [10]. Australia is one of the nations at the forefront of blockchain innovation with worldleading public and private sector projects such as the Australian Securities Exchange's CHESS replacement [11], Commonwealth Bank's Bond-i [12], IP Australia's IP Rights Exchange and Smart Trade Mark [13, 14] and Power Ledger's energy trading platform [15]. Australia also leads the secretariat to the technical committee developing international blockchain standards $[16,17]$.

Along with the emergence of blockchain technology, the demand for blockchain-related skills has been growing. The Bitcoin hype of 2017 sparked a boom in demand for blockchain-related skills, resulting in a competitive global hunt for blockchain employees [18].

For two quarters in a row (Q1-2 2018) blockchain led the list of the fastest growing skills in demand on the freelancing platform Upwork [19]. Blockchain first drew attention on the Upwork skills index in Q3 2017 as the second fastest growing skill followed by Bitcoin as the third. In Q4 2017, Bitcoin took the lead as the top skill [19] before losing its place to blockchain for Q1 and Q2 of 2018. Since then both Bitcoin and blockchain have slipped off the Upwork skills index list.

Similarly, job analytics firm Burning Glass Technologies (BGT) revealed a steady increase in the number of blockchain job postings between 2010 and 2014 in the United States of America (USA). The figure thereafter drastically increased, from 500 jobs in 2014 to almost 1,500 in 2015, before later spiking to 3,958 in 2017 [20].

In line with global trends, labour demand in Australia also experienced fast growth in blockchain-related jobs since 2014/2015 (see Figure 1). The number of job ads in 2015/2016 was 19 and grew almost by $215 \%$ in 2017/2018 to 408. The Australian market, being smaller and less developed than that of the USA, saw explosive growth two years later than the USA did and the number of blockchain job ads in the USA was almost 10 times higher than those in Australia (see Figure 1).

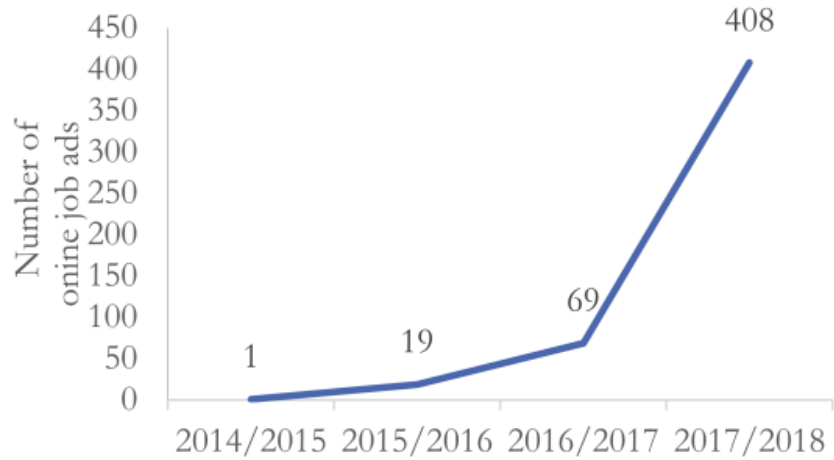

Figure 1. Blockchain-related online jobs ads in Australia, 2014/15-2017/18.

Source: BGT [20]

The end of 2017 marked the peak of global hype and inflated expectations for blockchain technology. The following year saw a deepening disillusionment heading into the infamous 'cryptowinter' (see Figure 2). In this period, blockchain began to be thought of as the most over-hyped technology since the beginning of the century. Voices questioning the applicability of blockchain, its maturity and effectiveness became increasingly prominent among business and government experts [21]. Media messages moved from 'blockchain can solve any problem' and 'all industries have use cases for blockchain’ [22, 23] in 2017 to more sober accounts of non-blockchain use cases [21, 24] with an occasional smattering of 'there are no good uses for blockchain' [25]. Additionally, a global survey of public and private sector leaders showed that early investments in blockchain did not realise their anticipated returns [26]. On average, the respondents expected a $24 \%$ return but only realised $10 \%$.

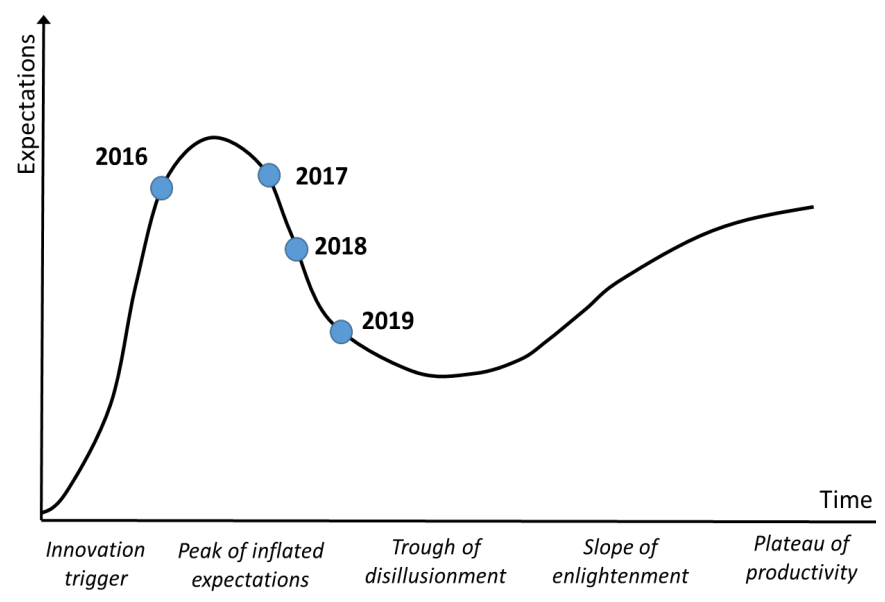

Figure 2. Approximate positions for blockchain technology along the Gartner Hype Cycle for emerging technologies, 2016-2019. 


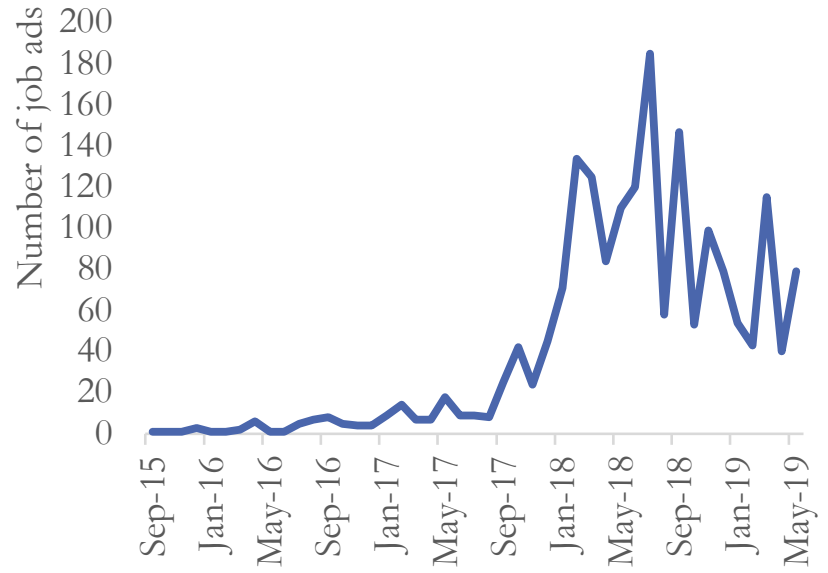

Figure 3. Blockchain-related online jobs ads in Australia by month, 2015-2019.

Source: Data61 Australian Skills Dashboard [27]

In Australia, crypto hype grew from 2015 until it peaked in 2018, as reflected in our observation of job ads posted monthly on the Adzuna Australia labour market platform (see Figure 3). Since then the demand for blockchain employees in Australia has decreased but remains relatively high. Globally, in January 2020 LinkedIn predicted blockchain will be the most in-demand hard skill in 2020 on the platform [28]. This may signal a recovery of blockchainrelated project investment and that the sector in general might be plateauing in the trough of disillusionment, and potentially recovering from it.

This is interesting in and of itself. But job openings contain more information that allows us to ask the still more interesting question: what does it mean to be a blockchain employee? We will now use the Australian labour market data to consider which skills are required for blockchain employees. We will explore blockchain-related job ads in two data sets on the Australian labour market (BGT's Labor Insight $^{\mathrm{TM}}$ data set [7] and the Data61 Australian Skills Dashboard [27]). This article extends on previous research by Data61 [7].

\section{Data exploration}

\section{Burning Glass'Technologies data set}

One data set was sourced from job analytics firm BGT [29]. BGT data have been used by government and private organisations in Australia and internationally to investigate skills transformation [30], job transitions [31, 32], supply and demand [33, 34], education and credentials [35] among other topics. BGT's Labor Insight ${ }^{\mathrm{TM}}$ data set includes job vacancy data from company websites, online job boards and other online resources available for web crawling. As of August 2018, BGT covered over 44,000 web page sources across
Australia, New Zealand, the United Kingdom, USA, Singapore and Canada. Once the data are collected, BGT applies natural language processing to remove duplicate job ads and classify job skills. BGT acknowledges their data may include duplicate or miscoded job ads. See [36] for a detailed method and skills taxonomy.

We filtered the Labor Insight ${ }^{\mathrm{TM}}$ data by searching for ads that included 'blockchain' as a keyword. The final data set included 497 job ads posted between July 2014 and June 2018.

\section{Data61 Australian Skills Dashboard data set}

The Data61 Australian Skills Dashboard data set provides a snapshot of the labour market [27]. This dashboard analyses job ad data provided by the labour market platform Adzuna Australia. The data set includes job ads listed directly on the Adzuna Australia platform, ads listed in Australia's major newspapers and ads 'scraped' from other available online resources. Scraped ads must pass a screening process before entering the Adzuna platform, to minimise the number of expired, duplicate or incomplete job ads. The Data61 Australian Skills Dashboard data set is further cleansed through natural language processing and human coding to remove any remaining job ads that are duplicate or are from unreliable sources [37, 38]. Skills required by job ads are categorised using the European Skills, Competences, Qualifications and Occupations skills taxonomy. The dashboard represents the Australian labour market in terms of occupational categories and geographic locations at the state and capital city level [38]. However, job ads in the state of Western Australia as well as 'blue collar' jobs may be underrepresented [38].

For the purposes of this article, the Adzuna data set was filtered with 'blockchain' as a keyword. The search returned 1,863 job ads posted between September 2015 and May 2019. We also qualitatively classified the job ad skills into 'soft' skills and 'hard' skills to determine the demanded skills mix in advertised positions.

\section{Observations from the Australian labour market for blockchain employees}

\section{Skills demand}

Examination of the Data61 Australian Skills Dashboard data set demonstrates that employers are looking for a combination of soft and hard skills in the blockchain workforce. The hard skills frequently mentioned in the blockchain-related job ads include computer technologies and more specifically knowledge of JavaScript and Internet of Things. Around half of the skills most frequently mentioned in the job ads, alongside blockchain, are soft skills including creative thinking, customer service, communication, as well as project management and leadership (see Figure 4). Moreover, 84.3\% 
of the job ads required a mix of both soft and hard skills (see Figure 5).

For a more detailed exploration of the required hard and soft skills, we looked at BGT job ads posted in 2017-2018. The data reveal the top technical skills desired from prospective blockchain employees (see Figure 6). The listed skills require a background in programming and/or mathematics.

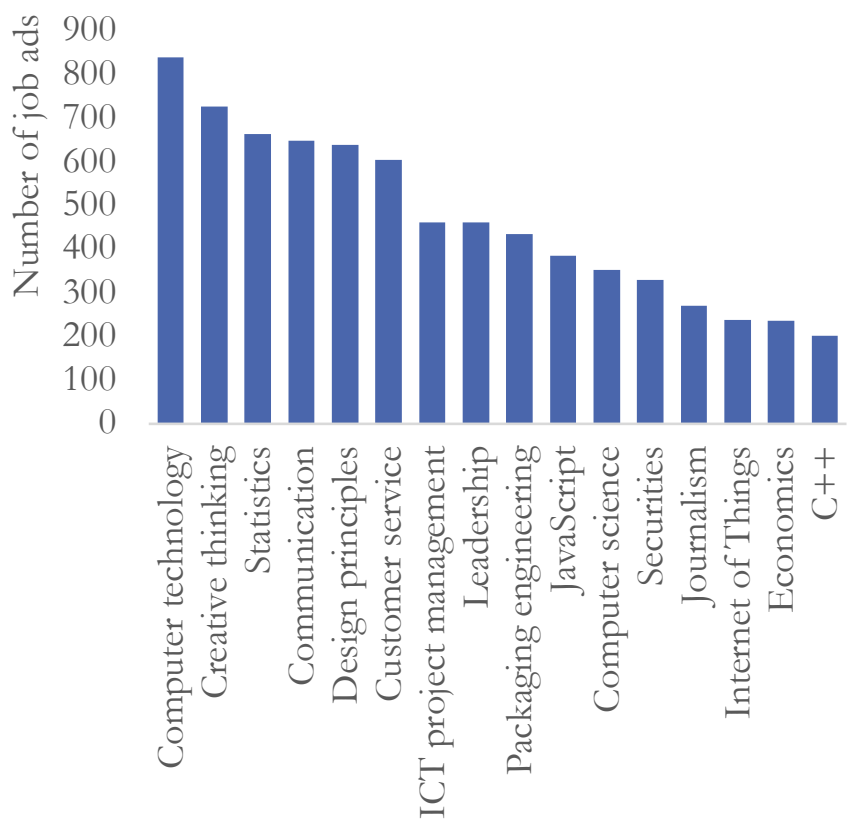

Figure 4. Top skills mentioned in Australian blockchain-related job ads between September 2015 and May 2019. Source: Data61 Australian Skills Dashboard [27]

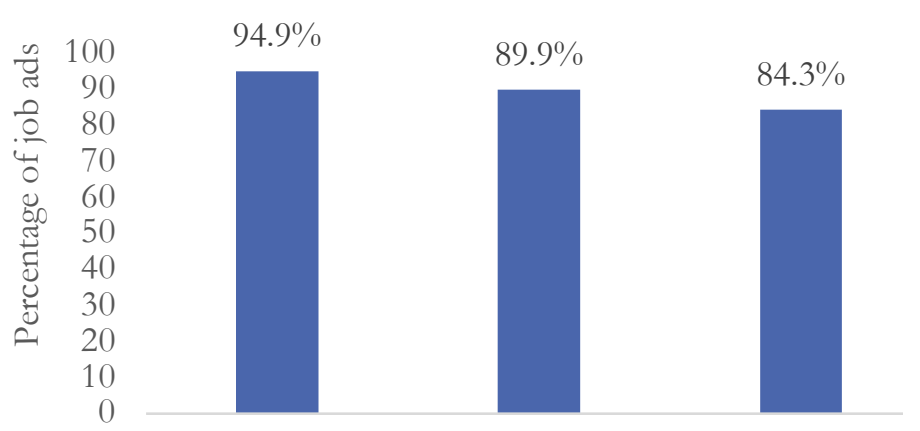

Job ads requiring Job ads requiring Job ads requirin at least 1 soft skill at least 1 hard skill at least 1 soft sk and 1 hard skil

Figure 5. Soft and hard skills mix of Australian blockchainrelated job ads between September 2015 and May 2019. Source: Data61 Australian Skills Dashboard [27] Note: $1.4 \%$ of the total job ads listed no skills and were excluded from this graph.

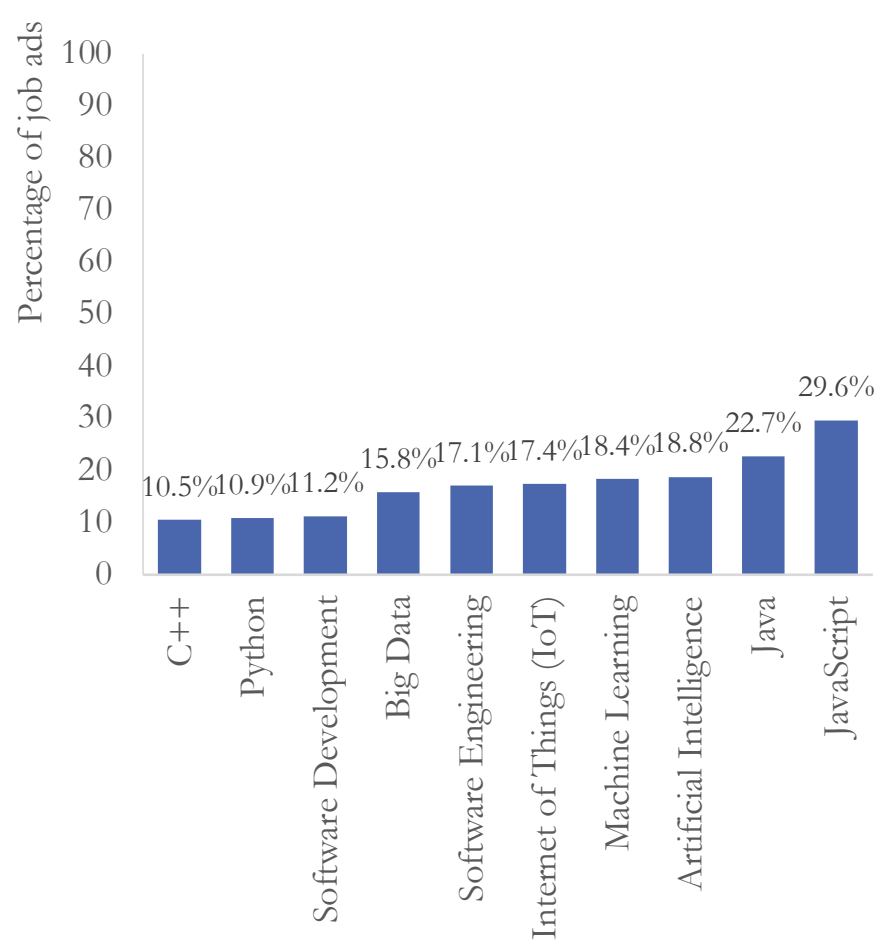

Figure 6. Top hard skills required in Australian blockchainrelated job ads between August 2017 and August 2018. Source: BGT data [7]

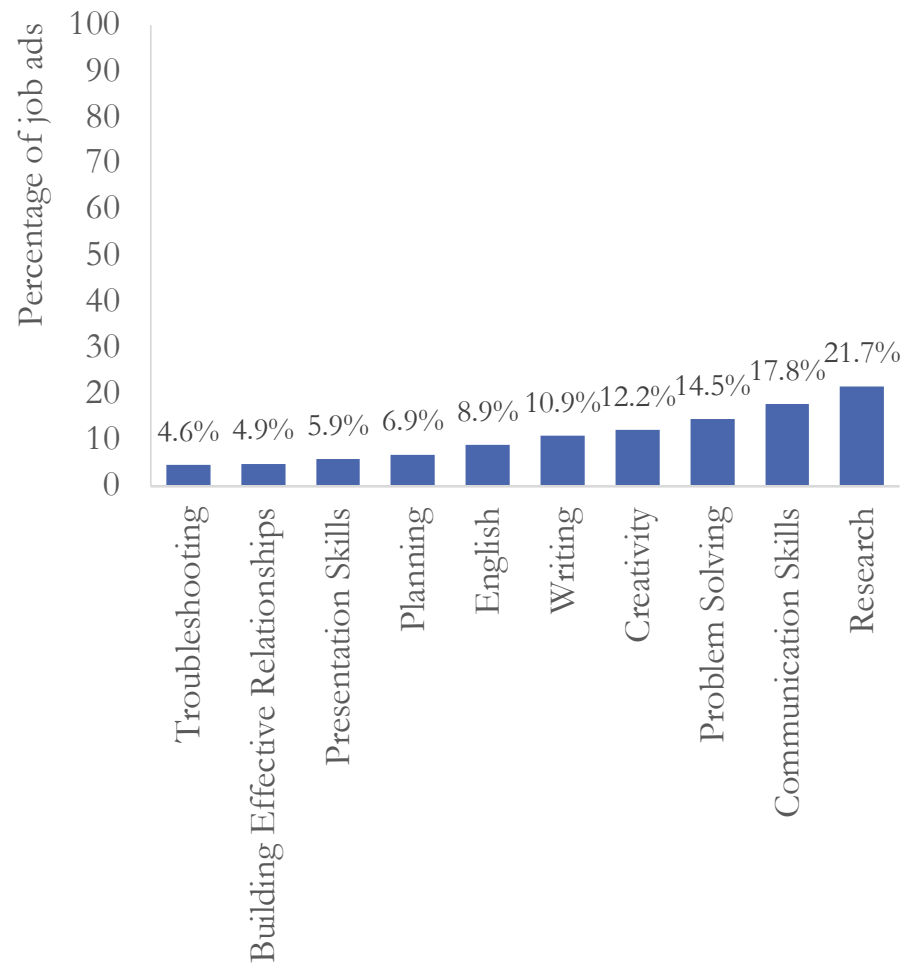

Figure 7. Top soft skills required in Australian blockchainrelated job ads between August 2017 and August 2018. Source: BGT data [7] 
The BGT data also show that there is demand for soft skills among blockchain employees (see Figure 7).

\section{Experience required}

In the BGT data, 161 job ads mentioned required experience (see Figure 10), with over half of the jobs requiring between three to five years of experience.

$$
\begin{array}{r|r|}
\text { No experience required } & 1.2 \% \\
0 \text { to } 2 \text { years } & 21.1 \% \\
3 \text { to } 5 \text { years } & 50.9 \% \\
6 \text { to } 8 \text { years } & 7.5 \% \\
9+\text { years } & 19.3 \% \\
& 0 \% \quad 20 \% \quad 40 \% \quad 60 \% \quad 80 \% 100 \% \\
\text { Percentage of job ads }
\end{array}
$$

Figure 8. Level of experience required in Australian block chain-related job ads between August 2017 and August 2018. Source: BGT data [7] Note: $68 \%$ of records have been excluded because they did not mention required experience. Therefore, this chart may not be representative of the full sample.

In the BGT data set, 107 blockchain-related job postings referenced a preferred field of study. The top majors that blockchain job ads required are listed in Figure 9.

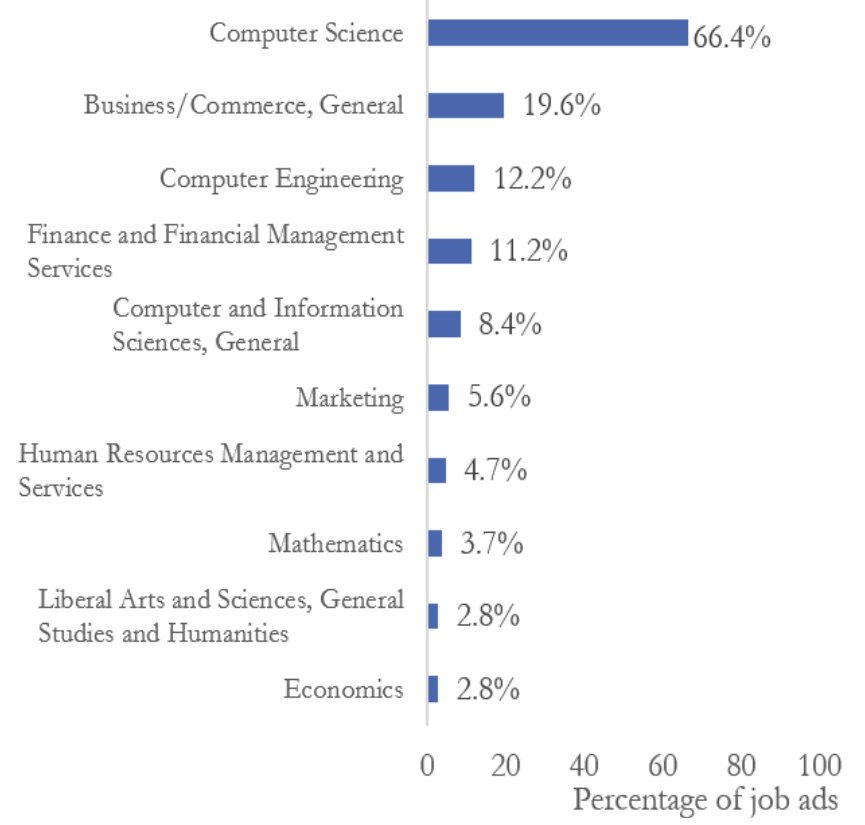

Figure 9. Top degrees required in Australian blockchainrelated job ads between August 2017 and August 2018. Source: BGT data [7]

Note: $77 \%$ of records have been excluded because they did not include a major. Therefore, this chart may not be representative of the full sample.

\section{Required educational qualifications}

The observed demand for skills was reflected in the desired level of educational qualifications for blockchain employees (see Figure 8). Over 9 in 10 blockchain jobs required either a bachelor's degree or an even higher level of education according to the BGT data.

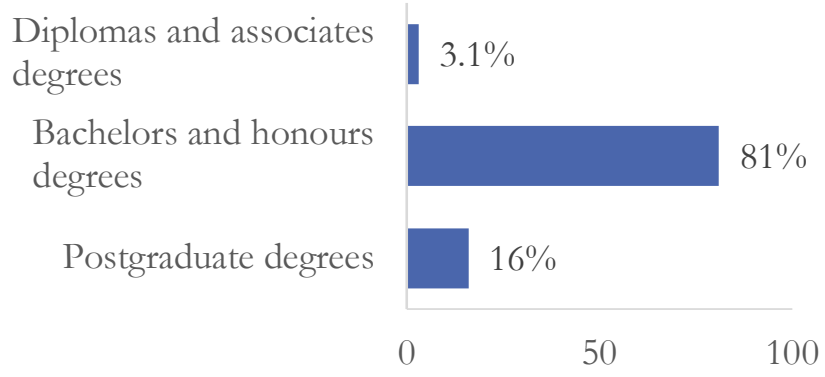

Figure 10. Qualifications required in Australian blockchainrelated job ads between August 2017 and August 2018.

Source: BGT data [7]

\section{Salary distribution of jobs}

Almost $60 \%$ of the jobs offered to pay blockchain employees above AU\$100,000 per year (see Figure 11). This is a higher wage level than most Professional job offers. Only around $45 \%$ of Professional jobs offered the same salary bracket. However, the data showed no difference in wage level between blockchain employees and Data Scientists and Software Engineers who have a relatively similar skill set to blockchain developers.

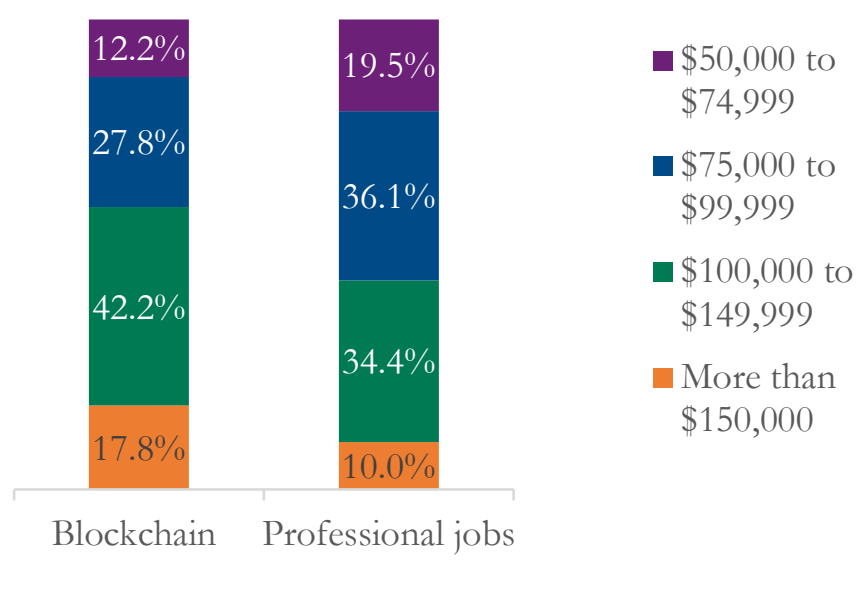

Figure 11. Salary distribution of jobs in blockchain and other Professional jobs between August 2017 and August 2018 (in Australian dollars). 
Source: BGT data [7]

Note: Professional jobs are defined as the jobs requiring at least a bachelor degree.

The picture of the in-demand blockchain workforce is therefore a somewhat interesting one for a technology-heavy sector building something akin to a digital utility. The typical blockchain employee at least in Australia is one who integrates hard technical skills and soft personal and enterprise skills. They are highly educated, typically with a formal higher degree in-hand.

\section{Explaining skills demand as a function of blockchain adoption challenges: behavioural institutional cryptoeconomics}

We can understand the observed skills demand for blockchainrelated jobs in Australia as a response to the challenge of securing blockchain adoption. Blockchain is a different technology to traditional technologies studied by economic theory as it is an institutional technology [6, 39]. Industrial, inter-firm productivity-enhancing technologies have tended to evolve at a relatively rapid rate compared to institutional technologies such as firms, markets, clubs, commons and governments that take decades and centuries to develop. However, blockchain as an institutional technology will be characterised by rapid, coordinated adoption.

To understand challenges being posed to blockchain adoption, we apply some game theory and behavioural science to round out the insights of institutional cryptoeconomics. We call this mix 'behavioural institutional cryptoeconomics'. It shows us that the key challenge to blockchain adoption is building capacity for adoption and then coordinating expectations across that population to facilitate rapid, coordinated adoption. It is the solution to this challenge- $-\mathrm{a}$ similar challenge to that faced by Facebook, Uber, Airbnb, Amazon, PayPal and YouTube in their early years - that reveals to us what the Australian labour market for blockchain employees may be responding to.

\section{Institutional cryptoeconomics: platforms and network externalities}

Institutional cryptoeconomics identifies that the defining characteristic of blockchain is not that it is a distributed ledger technology (DLT) $)^{2}$ per se, but rather that it is an institutional technology [6, 39]. It introduces a sixth archetype to the traditional five: markets, firms, governments, commons and clubs [40-43]. Such technologies require different kinds of governance, delimiting and enforcing the bounds of acceptable behaviour in society. The contention of institutional

2 Distributed ledger technologies (DLTs) are digital infrastructure that record and store data, and consensually share and synchronise the data through a network spanning multiple sites, institutions and/or geographies [1] ibid. cryptoeconomics is that blockchain presents a sixth institutional technology because it is differentiated by the nature of its emergence and operation [6, 44]. Blockchain protocols (such as Bitcoin, Ethereum and Monero) delimit a range of interactions on internet platforms that can be considered legitimate and integrated by a consensus algorithm into a record held by a network. The writing and actioning of blockchain protocols to support institutional governance of internet platforms, therefore almost by definition, emerges from a decentralised network and is actioned by that network. It does not require legitimation by government or some other centralised enforcement authority. It can be entirely supported by private entities. Blockchain is thus an institutional technology that allows for privatised emergent governance of internet-based platforms.

The defining problem in blockchain adoption, that makes it different from industrial technology adoption, is that, as a technology that enables institutional governance of internet platforms, it must, as with any platform technology, harness network externalities to achieve rapid, coordinated adoption [45-47]. This is not necessarily the case with industrial technologies [48-52]. But because platform technologies exist to enable and support interactions that would not otherwise be possible, they derive their value from the interactions that are possible within them. Therefore, the value of adopting a platform for interacting with others by any one individual or organisation is contingent upon its adoption by other individuals and organisations they might like to interact with. In economic theory we call this a network externality [5356] - the collective adoption of a particular technology affects the value an individual could realise from it.

\section{Applied game theory, network externalities and Schelling-point coordination}

Applied game theory allows us to identify why blockchain adoption needs to be rapid and coordinated. Achieving adoption of a platform governed by institutional technology is a special case of Schelling-point coordination [57]. Originally, Schelling-point coordination illustrated why the problem of disarmament is difficult to solve, because unilateral disarmament could be disastrous, and so all nuclear powers must simultaneously disarm (and maintain their disarmament). To obtain such an equilibrium, the various nuclear powers must therefore believe that all other nuclear powers will disarm simultaneously with them. Thus Schelling-point coordination becomes a problem of coordinating expectations between various nuclear powers to ensure simultaneous disarmament.

A similar problem is created by network externalities in the context of platform technology adoption and therefore the adoption of blockchains. The value of adopting a given internetbased platform for interaction subject to blockchain-based institutional governance is completely contingent on its adoption by others. Obtaining an equilibrium where a given platform and its blockchain are adopted therefore requires that 
there be a belief across the population that the population at large will adopt it. Hence, the adoption of blockchain as an institutional technology for platform governance depends on the coordination of expectations across the population of potential users that sufficiently many others in the population will adopt the platform and its blockchain. Lest those expectations be 'dashed' and the adoption 'fizzle', that coordination of expectations must support rapid, coordinated adoption of the internet-based platform for interaction subject to blockchainbased institutional governance under consideration.

\section{Applied behavioural science and restraining forces in blockchain adoption}

The problem of coordinating expectations is fundamentally predicated on human behaviour in a systemic context. Blockchain will not be adopted unless there is rapid, coordinated adoption at the systemic level.

Arguably the simplest formulation of psychological theory that is directly applicable to understanding the solution to this problem is that provided by Kurt Lewin [58]. Lewin sees behaviour as an equilibrium between driving and restraining forces that emerge from the interaction between motivation [59], cognition [60] and environment [61]. The challenge, Lewin suggests, when we approach problems of behaviour change, such as securing adoption of blockchain, is not to increase the driving forces towards that behaviour. The challenge is to reduce the restraining forces emerging from the interaction between motivation, cognition and environment that urge the individual away from that behaviour.

For restraining forces in blockchain adoption, there are two broad categories. For an individual or an organisation to adopt a platform subject to blockchain governance, they must be (1) able to adopt the platform as a system for interaction with others and (2) be willing to adopt the platform (see Figure 12).

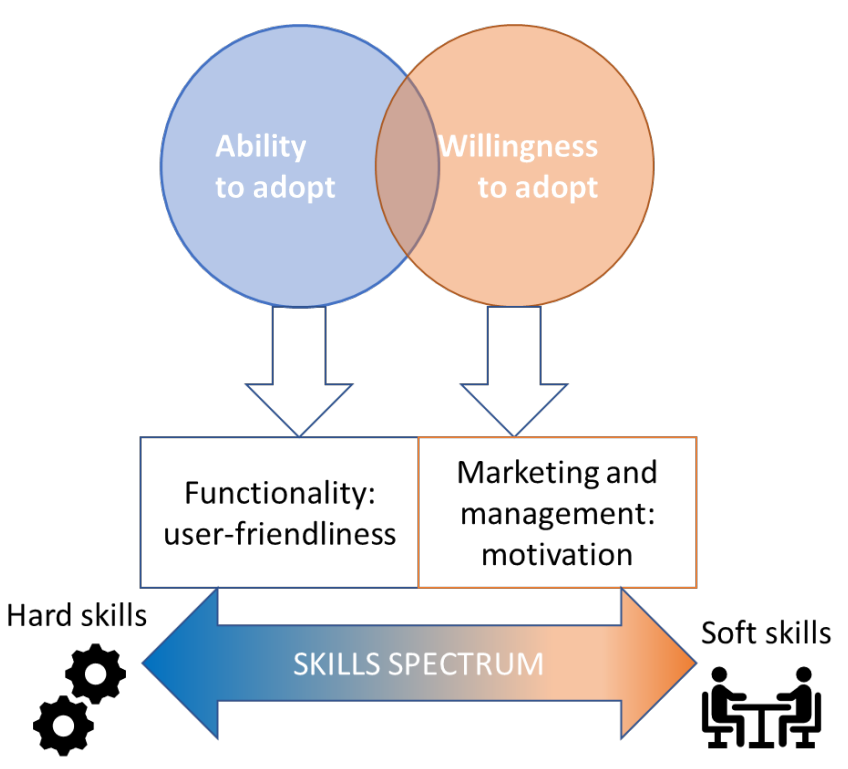

Figure 12. Overcoming restraining forces in blockchain adoption.

In terms of the ability to adopt a platform subject to blockchain governance, the first restraining force is the actual creation and functionality of the code itself.

Building the initial system can be difficult since it often requires collaboration from various users across networks, business units, jurisdictions and systems. The networked nature of blockchain also means that it will, typically, exist within a 'winner takes all' system-with dominance in systems and protocols often being gained by those able to grow rapidly in the initial phases and obtain first mover advantage [62]. The 'winner takes all' dynamic makes the collaboration delicate and challenging. As such, gaining collaboration to build the initial system often requires strong skills in strategic management. Delivering requires good communication to the technical team, so the system meets the requirements of the collaborators.

In the event they can achieve this, the technical team is likely to successfully build a system with basic functionality. But when human beings are involved, cognitively limited organisms, usability goes to a far deeper level than engineering alone. To maximise the likelihood of a blockchain platform's adoption, the platform itself must be designed to be user friendly enough so that any technical functioning of the platform is essentially invisible to the user experience. The more complex the platform is in terms of user experience, the greater the restraining forces against adoption, because the requisite cognitive capabilities to use the platform cannot be developed. World-class user experience design is necessary for developing capacity for blockchain adoption among a population of potential adopters. 
Continuing this, one step removed again from engineering concerns, the usability of a platform subject to blockchain governance depends on the complexity of the institutional arrangements to which it is subject. The more complex the institutional arrangements that govern the platform both internally ('on-chain') and externally ('off-chain'), especially due to external regulatory structures and again uncertain regulatory structures, the greater the restraining forces against adoption. Cognitive capabilities are necessary not only for the simple ability to use the platform on a functional level, but also for the ability to use it within the bounds of acceptability delimited by institutional governance. How many laws does one break simply because they are too complex for one unindoctrinated in the law to understand? Good institutional design and negotiation with external parties is needed to ensure the blockchain governance structure is usable enough for all potential adopters.

Now as to the willingness to adopt a platform subject to blockchain governance, this depends on the extent to which the cognitive dissonance [63] created by ideas about breaking with traditional platforms for interaction and embracing platforms subject to blockchain governance can be overcome. This cognitive dissonance presents a significant restraining force urging against adoption of blockchain technology, as it does with any new technology. But in the case of blockchainbased institutional technologies, the existence of network externalities and the pre-existence of established platforms (such as Amazon, Uber and YouTube) is particularly acute.

This restraining force is something that must be overcome by world-class strategic management and marketing of the design of a platform subject to blockchain governance. This strategic management and marketing must integrate design across all aspects of the platform from the functionality of the code itself to the user interface laid over it, and also integrate this design with strategic marketing that builds sufficient expectations (that will be validated) about the value of adopting the platform and its governance structure. Critically for the validation of these expectations, the strategic management and marketing of the design must be oriented to facilitating rapid, coordinated adoption en masse.

Unless this strategic management and marketing of design is strong, it will fail to build and/or validate expectations that reduce the restraining force of cognitive dissonance about the value of adopting a new blockchain-based platform. If that is the case, we will fail to see harnessing of network externalities to leverage rapid, coordinated adoption of the platform subject to blockchain governance, and thus we will fail to see adoption at all. Hence astute strategic thinking in management and marketing of the platform and blockchain design is critical for blockchain adoption.

Behavioural institutional cryptoeconomics: labour market demand for skills as a function of the adoption problem
We are now in a position to understand what we might be observing in the Australian labour market data as reflecting the market's response to this problem. We saw that as a technology for institutional governance of internet-based platforms, the adoption of blockchain technology is subject to network externalities that must be harnessed and overcome by Schelling-point coordination. We saw how the achievement of this Schelling-point coordination required the overcoming of restraining forces against the adoption of blockchain technology by world-class user experience design, institutional design and astute strategic thinking in the management, marketing and design of platforms subject to blockchain-based governance.

To reduce restraining forces in blockchain adoption, it is therefore necessary to integrate software engineering with insights from user experience, negotiation, lawmaking, political theory, strategy, management, marketing and design. While different employees in a development team may differ in their skills and strengths, it will be necessary for at least one to have an integrated skill set across all of them to facilitate their integration across the whole team. At least one employee, in other words, will need to 'speak the language' of hard and soft skills to facilitate their integration, and this will necessarily require them to have some proficiency in both. Only if this integration of soft skills and hard skills occurs will we observe the development of capacity and the coordination of expectations necessary to support rapid, coordinated adoption of blockchain as an institutional technology for internet-based platforms.

\section{Discussion}

Our exploration of Australian labour market data would appear to provide hope for blockchain enthusiasts if the observations are a function of the market responding to the core problem in blockchain adoption. If we were going to observe the adoption of blockchain as an institutional technology for internet platform governance, we ought to be observing the emergence of demand for employees who are skilled in communication strategy, management, marketing and user experience as well as those who are skilled in software engineering. Indeed, we ought to be observing a demand for employees who can integrate soft skills with hard skills. Our observations from the Australian job ad data provide some evidence that this may be occurring, revealing a demand for hard skills, soft skills and integrated skill sets from blockchain employees.

These results accord with the general findings of empirical studies in labour economics as they track the emergence of the digital economy. As digital technologies advance and more jobs are expected to be replaced or disrupted by automation, we are observing growing demand for technical skills and programming universally across the economy. However, the demand for soft skills is also growing, and in many cases outstripping the demand for technical skills [64]. Based on the data insights and theoretical frame of behavioural institutional cryptoeconomics, we suggest we are observing at least in Australia a labour market 
response to the challenge of securing blockchain adoption. This might suggest that the technology is poised to emerge from the trough of disillusionment as a new generation of blockchain employees enter the sector. These employees may develop a stronger integration between software design through the application of hard technical skills, and securing the platform's adoption through the application of soft skills. This may promote rapid, coordinated adoption of blockchain by the overcoming of restraining forces contributed to by network externalities and usability, and cause the technology to become more integrated into the technological base of the economy at its core, rather than as a peripheral technology.
Our data insights and theoretical frame also suggests that blockchain adoption may require blockchain employees who can help build the combination of technology and complementary skills required for different groups from blockchain users to blockchain developers. A simple model of this integrated skills hierarchy that we suggest needs to be built and perhaps is being built as presented in Figure 13. Blockchain leaders will need to understand the opportunities and limitations of the technology to strategically develop, market and manage blockchains as a software as well as develop a population that can co-develop and use it.

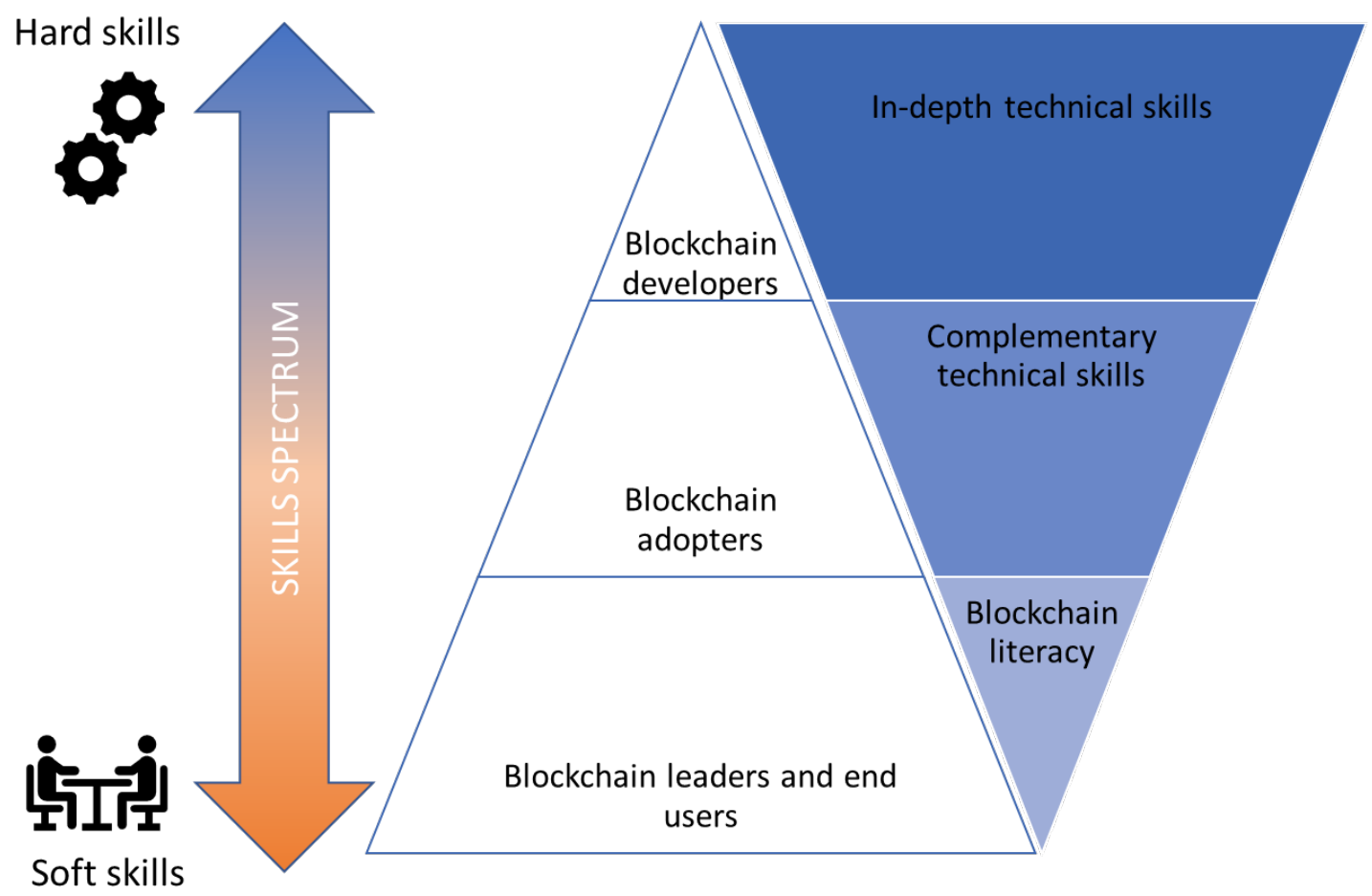

Figure 13. Hierarchy of blockchain technical skills for blockchain developers, adopters and users.

Blockchain developers and adopters will play an essential role in further development and implementation of the new technology across the economy and will rely on blockchain knowledge and industry expertise, contributing to the building capability for adoption. Blockchain leaders, community leaders and end users would benefit from 'blockchain literacy' or a broader understanding of how the technology works. While the usability of the system should make its technical functioning invisible, the end users will need to understand blockchain's value proposition and key differences to existing systems to build expectations of coordinated adoption. Complementary soft skills will be crucial for adopting companies and industries to fit the new approaches with existing legacy systems and to ensure the technology fit for jobs, teams and industry-specific requirements.

One pressing issue for the development and uptake of blockchain technology is the supply of a qualified workforce to meet the growing demand for blockchain development. Australia might produce fewer potential blockchain employees than other countries as Australia has fewer Information and Computer Technology (ICT) graduates than countries such as Singapore, Finland and New Zealand. In these countries, more than $6 \%$ of all students graduate with ICT qualifications compared to only $3.5 \%$ in Australia [65]. The continuing expansion of blockchain outside the ICT industry, we suggest, will open large markets for educational providers in Australia and internationally. The growing demand for quality blockchain education therefore forms a market niche for accredited Australian educational providers.

\section{Limitations and further research directions}

This article explicitly focuses on blockchain as the most popular DLT. There are two reasons for this narrow focus: (1) compared to blockchain, DLT as a term (and key word) is rarely present in 
the online job ad data that we used, and (2) DLTs are not tracked by the Gartner Hype Cycle. Although we suspect that our theoretical frame can be applied more broadly to DLTs, our article has not specifically investigated DLTs.

Given that blockchain technology is new and it is still early in the hype cycle, there is a lack of high-quality data to deeply understand the challenges to blockchain development and adoption. This makes it difficult to perform much more than the descriptive analyses conducted in this study.

Another limitation of the current study lays in the nature of job ad data and skills classifications. Job ads represent what skills employers demand from employees, but does not necessarily reflect the skills of those who are interviewed or hired, neither do they directly reflect the roles, tasks and responsibilities of those hired.

Lastly, in our approach, we used theories to explain what we observed in the data. The next logical step would be to validate our explanations should additional or more detailed data become available. Future research could therefore target collection of higher-quality and larger data sets and conduct inferential statistical analysis. It would also be interesting to perform a comparative analysis across international blockchain job ad data sets, especially for regions with larger labour markets such as the USA.

Another direction for future research would be a study of labour market dynamics as well as constitution and transformations of skill sets for blockchain (and broader DLTs) in comparison with other emerging technologies such as artificial intelligence or quantum computing.

\section{Conclusion}

This article contributed to the evidence-based blockchain literature by examining the in-demand blockchain workforce as (and if) the technology moves through the trough of disillusionment into a plateau of productivity. The exploration of Australian labour market data showed that the in-demand blockchain workforce is well compensated, experienced and highly educated, with a mix of hard software engineering skills as well as soft enterprise and personal skills. To explain the skills demand, we used behavioural institutional cryptoeconomics which theorises that coordinating expectations of blockchain adoption among developers and users is necessary to create network externalities to facilitate rapid, coordinated adoption. We explained that a mix of soft and hard skills are necessary to overcome the challenge of coordinating expectations. More specifically, we argued that hard software engineering skills, together with world-class user experience design and institutional design, are needed to create a functioning blockchain system that can be adopted by end users. Furthermore, strategic management and marketing are needed to give end users the motivation to adopt. We also argued that mass adoption also requires blockchain leaders and end users to gain blockchain literacies, as this helps them understand the platform's value proposition, thus boosting their motivation to adopt. The job market demand for both soft and hard skills showed that the blockchain industry, at least in Australia, is aware of the need for a skills mix. Gaining and maintaining this skilled workforce may be what makes or breaks blockchainwhether adoption fizzles due to a lack of strategic management, usability and marketability, or whether it overcomes these challenges and becomes the mass-adopted institutional technology that many are hopeful of.

\section{Competing Interests:}

None.

Ethical approval:

Not applicable.

Author's contribution:

Yes

Funding:

The Australian Computer Society funded the previous foundational research project resulted in the publication of "Blockchain 2030: A look at the future of blockechain in Australia" report. This funding allowed the researchers to access to the Burning Glass Technologies data set.

\section{Acknowledgements:}

We thank Dr Claire Mason and Dr Caron Chen from CSIRO's Data61 for their assistance in exploring the Data61 Australian Skills Dashboard, as well as Dr Kelly Trinh for her early stage observations of the BGT data set. We also thank Dr Lucy Cameron, Dr Mark Staples and Dr Claire Mason from CSIRO's Data61 for reviewing the draft manuscript.

We are grateful to the peer reviewers for reviewing the draft manuscript and providing constructive criticism and helpful comments.

The authors also acknowledge the kind contribution of Adzuna Australia's data sets to this research.

We thank Burning Glass Technologies for providing the Labor Insight ${ }^{\mathrm{TM}}$ data set.

\section{References:}

[1] P. Schueffel, N. Groeneweg, and R. Baldegger, The Crypto Encyclopedia. Bern, Switzerland: Growth Publisher, 2019.

[2] M. Staples et al., Risks and Opportunities for Systems Using Blockchain and Smart Contracts. Sydney: Commonwealth Scientific and Industrial Research Organisation, 2017.

[3] C. Catalini and J. S. Gans, Some Simple Economics of the Blockchain, Rotman School of Management Working Paper No. 2874598. MIT Sloan Research Paper No. 5191-16. Cambridge: National Bureau of Economic Research, 2016.

[4] D. W. Allen, A. Berg, and B. Markey-Towler, "Blockchain and supply chains: V-form organisations, value redistributions, de-commoditisation and quality proxies," Journal of the British Blockchain Association, vol. 2, no. 1, pp. 57-65, February 2019. 
[5] D. Tapscott and A. Tapscott, "How blockchain will change organizations," MIT Sloan Management Review, Dec. 7, 2016. [Online]. Available: https://sloanreview. mit.edu/. [Accessed: March 26, 2020].

[6] S. Davidson, P. De Filippi, and J. Potts, "Blockchains and the economic institutions of capitalism," Journal of Institutional Economics, vol. 14, no. 4, pp. 639-658, January 2018.

[7] A. Bratanova et al., Blockchain 2030: A look at the future of blockchain in Australia. Brisbane, Australia: Commonwealth Scientific and Industrial Research Organisation, 2019.

[8] A. Linden and J. Fenn, Understanding Gartner's Hype Cycles, Strategic Analysis Report No. R-20-1971. Stamford, CT: Gartner, 2003.

[9] R. Sokolowski, Introduction to Phenomenology. Cambridge: Cambridge University Press, 2000.

[10] T. Wilson, "Big corporates back crypto 'plumbing' despite currency caution," Reuters, Apr. 18, 2019. [Online]. Available: https://www.reuters.com/. [Accessed March 26, 2020].

[11] Australian Securities Exchange, "CHESS replacement," $A S X$, Sept., 2016. [Online]. Available: https://www. asx.com.au/. [Accessed: March 26, 2020].

[12] Commonwealth Bank of Australia, "Commonwealth Bank and QTC create first Government bond using blockchain," Newsroom Home, Jan. 25, 2017. [Online]. Available: https://www.commbank.com.au/. [Accessed: March 26, 2020].

[13] M. Burn, CWS/6 IP Australia's Blockchain Initiatives. Canberra, Australia: Intellectual Property Australia, 2018.

[14] M. Bacina, "Trade marks and blockchain: Technology update," Insight, July 1, 2019. [Online]. Available: https:// piperalderman.com.au/. [Accessed: March 26, 2020].

[15] Power Ledger, "Energy, reimagined," Power Ledger, June 2016. [Online]. Available: https://powerledger.io/. [Accessed: March 26, 2020].

[16] Bitcoin.com.au, "How Australia is leading the world in blockchain standards," Bitcoin Australia, Aug. 9, 2018. [Online]. Available: https://bitcoin.com.au/. [Accessed: March 26, 2020].

[17] A. Coyne, "Australia to take global lead on blockchain standards," ITNews, Sept. 15, 2016. [Online]. Available: https://www.itnews.com.au/. [Accessed March 26, 2020].

[18] C. Lim, Y. Wang, J. Ren, and S.-W. Lo, "A review of fast-growing blockchain hubs in Asia," Journal of The British Blockchain Association, 9959, August 2019.

[19] Upwork, "The fastest-growing skills on Upwork: Q4 2017," Upwork, May 1, 2018. [Online]. Available: https://www.upwork.com/. [Accessed: March 26, 2020].

[20] S. Bittle, "Job postings for blockchain skills double over 2016," Burning Glass Technologies Blog, Oct. 30, 2017. [Online]. Available: https://www.burning-glass.com/. [Accessed: March 26, 2020].
[21] M. Bellmas, "Is blockchain a false idol?," ANZ Insights, March 2019. [Online]. Available: https:// institutional.anz.com/. [Accessed: March 1, 2020].

[22] E. Mesropyan, "30 non-financial use cases of blockchain technology," Medici, Dec. 18, 2017. [Online]. Available: https://www.gomedici.com. [Accessed: March 26, 2020].

[23] K. Doubleday, "Blockchain for 2018 and beyond: A (growing) list of blockchain use cases," Medium, Jan. 30, 2018. [Online]. Available: https://medium.com/. [Accessed: March 26, 2020].

[24] J. Bajkowski, “ANZ rips apart blockchain, catalogues its big list of non-uses," ITNews, March 25, 2019. [Online]. Available: https://www.itnews.com.au/. [Accessed March 26, 2020].

[25] K. Stinchcombe, "BankThink: Don't believe the hype: There are no good uses for blockchain," American Banker, Jan. 2, 2018. [Online]. Available: https://www. americanbanker.com/. [Accessed March 26, 2020].

[26] World Economic Forum and Accenture, Building Value with Blockchain Technology: How to evaluate blockchain's benefits. Geneva: World Economic Forum, 2019.

[27] C. Mason, Chen, C., Wan, S., Trinh, K., Duenser, A., Sparks, R., Walker, G., Zhao, Y., Burns, S., Reeson, A.,

Jin B., Naughtin, C., Data61 Australian Skills Dashboard, Australia: Commonwealth Scientific and Industrial Research Organisation, 2019. [Dataset]. Available: https://dmorg.csiro.au. [Accessed: Jan. 29, 2020].

[28] B. Anderson, "The most in-demand hard and soft skills of 2020," LinkedIn Talent Blog, Jan. 9, 2020. [Online]. Available: https://business.linkedin.com/. [Accessed: March 26, 2020].

[29] Burning Glass Technologies, Labor Insight ${ }^{\mathrm{TM}}$ Real-Time Labor Market Information Tool, Boston: Burning Glass Technologies, 2018. [Dataset]. Available: https://www.burning-glass.com/. [Accessed: Aug. 30, 2018].

[30] Department of Employment, Skills, Small and Family Business, Reskilling Australia: A data-driven approach. Canberra, Australia: Department of Employment, Skills, Small and Family Business, 2019.

[31] L. Wheelahan and G. Moodie, "Vocational education qualifications' roles in pathways to work in liberal market economies," Journal of Vocational Education \& Training, vol. 69, no. 1, pp. 10-27, March 2017.

[32] World Economic Forum, Towards a Reskilling Revolution: A future of jobs for all. Geneva: World Economic Forum, 2018.

[33] S. Miller and D. Hughes, The Quant Crunch: How the demand for data science skills is disrupting the job market. Boston: International Business Machines Corporation, 2017.

[34] Deloitte, The Path to Prosperity: Why the future of work is human. Melbourne, Australia: Deloitte, 2019. 
[35] ExcelinEd and Burning Glass Technologies, Credentials Matter - Report 1: A national landscape of high school student credential attainment compared to workforce demand. New York: ExcelinEd and Burning Glass Technologies, 2019.

[36] Burning Glass Technologies, Mapping the Genome of Jobs: The Burning Glass skills taxonomy. Boston: Burning Glass Technologies, 2019.

[37] Y. Zhao and C. Chen, Duplicate Detection from Online Job Advertisements. Canberra, Australia: Commonwealth Scientific and Industrial Research Organisation, 2019.

[38] A. Duenser and C. Mason, Evaluating Online Job Ads as Indicators of Demand for New Workers:

Characterising strengths and weaknesses. Australia: Commonwealth Scientific and Industrial Research Organisation, 2020.

[39] B. Markey-Towler, "Anarchy, blockchain and utopia: A theory of political-socioeconomic systems organised using blockchain," Journal of the British Blockchain Association, vol. 1, no. 1, pp. 1-9, March 2018.

[40] O. E. Williamson, The Economic Institutions of Capitalism. New York: Free Press, 1985.

[41] J. M. Buchanan, "An economic theory of clubs," Economica, vol. 32, no. 125, pp. 1-14, February 1965.

[42] J. M. Buchanan and G. Tullock, The Calculus of Consent, Vol. 3. Ann Arbor, MI: University of Michigan Press, 1962.

[43] E. Ostrom, Governing the Commons: The evolution of institutions for collective action. Cambridge: Cambridge University Press, 1990.

[44] D. Allen, C. Berg, B. Markey-Towler, M. Novak, and J. Potts, "Blockchain and the evolution of institutional technologies: Implications for innovation policy," Research Policy, vol. 49, no. 1, 103865, February 2020.

[45] A. McAfee and E. Brynjolfsson, Machine, Platform, Crowd: Harnessing our digital future. New York: W. W. Norton \& Company, 2017.

[46] W. J. Luther, "Cryptocurrencies, network effects, and switching costs," Contemporary Economic Policy, vol. 34, no. 3, pp. 553-571, July 2016.

[47] G. G. Parker, M. W. Van Alstyne, and S. P. Choudary, Platform Revolution: How networked markets are transforming the economy and how to make them work for you. New York: W. W. Norton \& Company, 2016.

[48] K. Dopfer, J. Foster, and J. Potts, "Micro-meso-macro," Journal of Evolutionary Economics, vol. 14, no. 3, pp. 263-279, July 2004.

[49] G. Dosi, "Technological paradigms and technological trajectories: A suggested interpretation of the determinants and directions of technical change," Research Policy, vol. 11, no. 3, pp. 147-162, June 1982.

[50] J. S. Metcalfe, J. Foster, and R. Ramlogan, “Adaptive economic growth," Cambridge Journal of Economics, vol. 30, no. 1, pp. 7-32, January 2005.
[51] J. S. Metcalfe, Evolutionary Economics and Creative Destruction. London: Routledge, 1998.

[52] R. R. Nelson and S. G. Winter, An Evolutionary Theory of Economic Change. Cambridge: Harvard University Press, 2009.

[53] M. Rysman, "The economics of two-sided markets," Journal of Economic Perspectives, vol. 23, no. 3, pp. 125-43, August 2009.

[54] M. L. Katz and C. Shapiro, "Network externalities, competition, and compatibility," American Economic Review, vol. 75, no. 3, pp. 424-440, June 1985.

[55] M. L. Katz and C. Shapiro, "Systems competition and network effects," Journal of Economic Perspectives, vol. 8, no. 2, pp. 93-115, May 1994.

[56] M. L. Katz and C. Shapiro, "Technology adoption in the presence of network externalities," Journal of Political Economy, vol. 94, no. 4, pp. 822-841, August 1986.

[57] T. Schelling, The Strategy of Conflict. Cambridge: Harvard University Press, 1960.

[58] K. Lewin, Field Theory in Social Science: Selected theoretical papers. Oxford: Harpers, 1951.

[59] H. A. Simon, "Motivational and emotional controls of cognition," Psychological Review, vol. 74, no. 1, pp. 2939, January 1967.

[60] H. A. Simon, "From substantive to procedural rationality," in Method and Appraisal in Economics, S. Latsis, Ed. Cambridge: Cambridge University Press, 1976, pp. 129-148.

[61] H. A. Simon, "Rational choice and the structure of the environment," Psychological Review, vol. 63, no. 2, pp. 129-138, March 1956.

[62] D. MacDonald-Korth, V. Lehdonvirta, and E. T. Meyer, The Art Market 2.0: Blockchain and financialisation in visual arts. Oxford and London: University of Oxford and The Alan Turing Institute, 2018.

[63] L. Festinger, A Theory of Cognitive Dissonance. Stanford, CA: Stanford University Press, 1962.

[64] S. Hajkowicz, A. Reeson, L. Rudd, A. Bratanova, L. Hodgers, and C. Mason, Tomorrow's Digitally Enabled Workforce: Megatrends and scenarios for jobs and employment in Australia over the coming twenty years. Brisbane, Australia: Commonwealth Scientific and Industrial Research Organisation, 2016.

[65] United Nations Educational, Scientific and Cultural Organization Institute for Statistics, UIS.Stat (Education, full dataset), Montreal: UNESCO Institute for Statistics, 2019. [Dataset]. Available: http://data. uis.unesco.org/. [Accessed: Jan. 3, 2019]. 